ORIGINAL ARTICLE

\title{
Outcome of children with neuromuscular disease admitted to paediatric intensive care
}

\author{
K Yates, M Festa, J Gillis, K Waters, K North
}

Arch Dis Child 2004;89:170-175. doi: 10.1136/adc.2002.019562

See end of article for authors' affiliations

.....................

Correspondence to: Dr J Gillis, Paediatric Intensive Care, The Children's Hospital at Westmead, Locked Bag 4001, Westmead NSW 2145, Australia; jong@ chw.edu.au

Accepted 17 April 2003

\begin{abstract}
Aims: To determine the outcome of children with neuromuscular disease (NMD) following admission to a tertiary referral paediatric intensive care (PICU).

Methods: All children with chronic NMD whose first PICU admission was between July 1986 and June 2001 were followed up from their first PICU admission to time of study. The outcomes recorded were death in or outside of PICU, duration of PICU admission, artificial ventilation during admission and following discharge from PICU, and readmission to PICU.

Results: Over 15 years, 28 children were admitted on 69 occasions. Sixteen (57\%) children had more than one admission. The median duration of PICU admission was 4 days (range 0.5-42). Twenty three per cent of unplanned admissions resulted in the commencement of respiratory support that was continued after discharge from the PICU. Severity of functional impairment was not associated with longer duration of stay or higher PRISM scores. Ten children (36\%) died, with four (14\%) deaths in the PICU. A higher proportion of children with severe limitation of function were among children that died compared to survivors. Conclusion: Most children with NMD admitted to the PICU recover and are discharged without the need for prolonged invasive ventilation. However, in this group of children, the use of non-invasive home based ventilation is common and they are likely to require further PICU admission.
\end{abstract}

A cute respiratory insufficiency is a common complication of chronic neuromuscular disorders (NMD) such as Duchenne muscular dystrophy (DMD) or spinal muscular atrophy (SMA). A common fear is that once intubated for an acute illness, children with NMD will not recover to be weaned from ventilation. ${ }^{1}$ In a UK study, $27 \%$ of all PICU admissions requiring ventilation for more than 28 days after an acute illness had an underlying neuromuscular disorder, and $45 \%$ of this group died. ${ }^{2}$

No study has specifically examined the outcome of children with NMD after admission to the PICU. The aim of this study is to document the length of stay, frequency of ongoing respiratory support, and survival of children with NMD admitted to our PICU over the past 15 years.

\section{METHODS}

We conducted a retrospective chart review, in the setting of a 15-bed tertiary referral PICU. The study was approved by the ethics committee of the Children's Hospital at Westmead. All children with NMD whose first admission to the PICU was in the period July 1986 to June 2001 were identified from the PICU database. The intensivist on duty completes this database at the time of PICU discharge, listing reasons for admission and underlying diagnoses. NMD was defined as any child with a neuropathy or myopathy causing weakness. We excluded all children with acute neuromuscular disorders such as Guillain-Barré syndrome, chemotherapy induced peripheral neuropathy, and myopathy secondary to critical illness.

Case notes were identified from the database and reviewed. Clinical information obtained from the medical records included diagnosis, level of function, respiratory support before admission and on discharge from PICU, length of PICU stay, duration of intubation, and duration of noninvasive ventilation. Continuous ventilation, used during wakefulness and sleep, was distinguished from nocturnal ventilation. Level of function at the time of admission was classified into four categories: normal, mild (mobile but difficulty with some skills, for example, running or climbing stairs), moderate (unable to walk, delayed milestones), or severe (older children unable to sit, infants with minimal spontaneous movement) impairment compared to their age appropriate gross motor milestones.

Paediatric risk of mortality scores (PRISM) $)^{3}$ were calculated prospectively on all PICU admissions from 1990. Information on follow up was collected from the medical records.

Admissions were recorded as planned or unplanned. Planned admissions were defined as those organised prior to a child undergoing an elective surgical procedure or admissions arranged in conjunction with the respiratory support service to commence nocturnal non-invasive positive pressure ventilation (NIPPV). All other admissions were classified as unplanned. This included children with acute illness referred from the hospital wards or presenting to the hospital emergency department, children transferred from district hospitals following respiratory arrest, and those who unexpectedly could not be extubated postoperatively. Acute respiratory infection was defined as a positive culture from the respiratory tract within 48 hours of admission or any two of the following: upper respiratory tract infection (URTI) symptoms, fever, raised white cell count. Children known to have chronic colonisation of the respiratory tract were not considered to have an acute infection unless a new organism was identified. Follow up information included duration of survival after the first PICU admission, number of readmissions to the PICU, later commencement of respiratory support, and death following discharge.

Abbreviations: DMD, Duchenne muscular dystrophy; IQR, interquartile range; NIPPV, non-invasive positive pressure ventilation; NMD, neuromuscular disease; PICU, paediatric intensive care unit; PRISM, paediatric risk of mortality scores; RSV, respiratory syncytial virus; SMA, spinal muscular atrophy; URTI, upper respiratory tract infection 
Years from 1 st admission

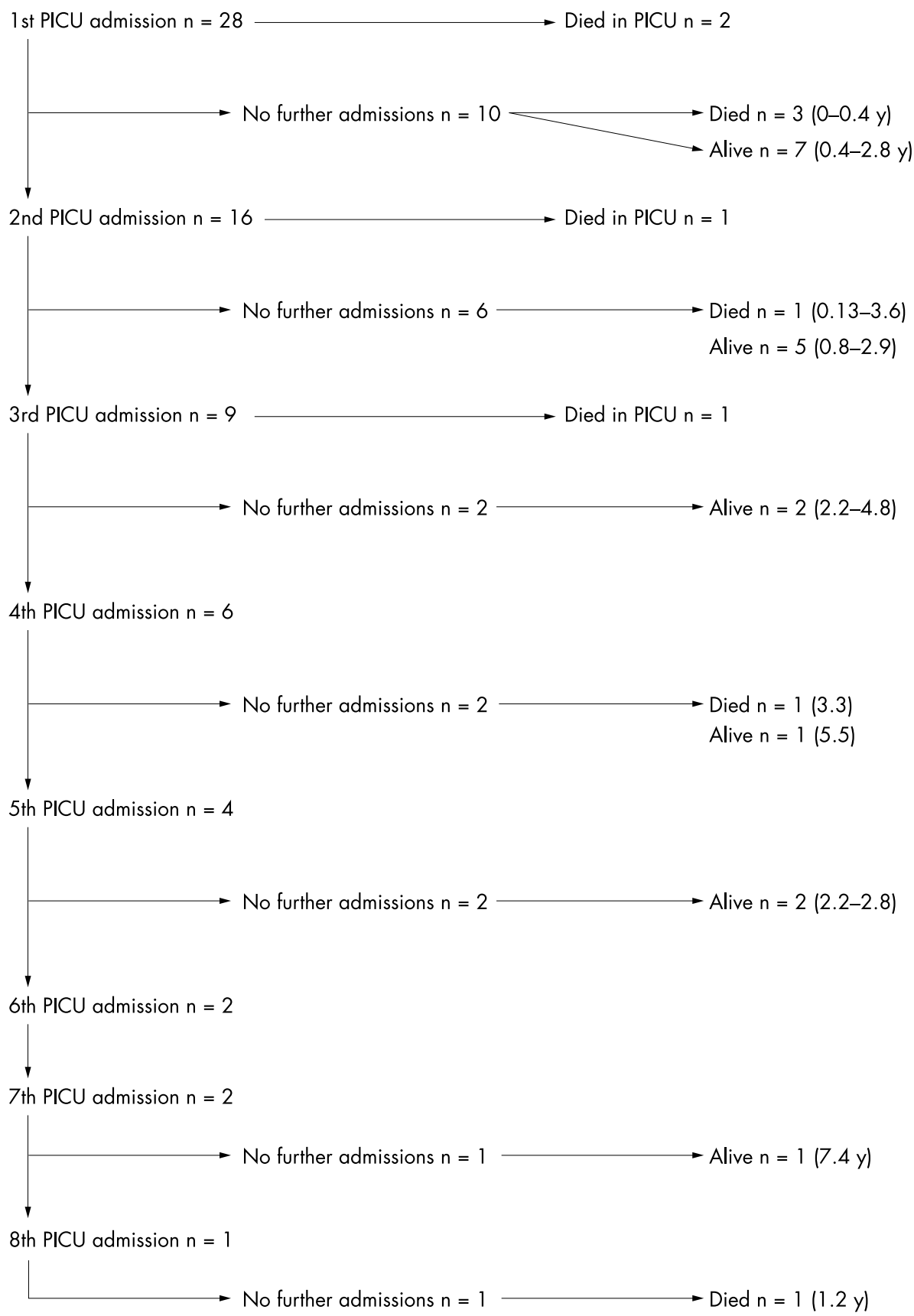

Figure 1 Follow up from first admission (planned and unplanned).

\section{Analyses}

Data failing tests of normality were analysed using nonparametric tests. The Mann-Whitney test was used for two independent samples and the Kruskall-Wallis test for variables with more than two groups. Unless otherwise stated, data are expressed as median with lst and 3rd interquartile range (IQR). A p value $<0.05$ was considered statistically significant. Data were analysed using Microsoft Excel 97 and SPSS (version 8.0).

\section{RESULTS}

Twenty eight children with NMD were admitted to the PICU for the first time during the study period (table 1).
Median age at first admission was 3 years 2 months (range 3 months to 19 years 5 months). Eighteen children (64\%) were male. Eleven (39\%) had severe limitation of function, seven $(25 \%)$ moderate, eight $(29 \%)$ mild, and two $(7 \%)$ had normal skills. Two (7\%) died during their first admission and $26(83 \%)$ were discharged (see fig 1 ). Of the 26 discharged from their first admission, 16 (62\%) required at least one further PICU admission. There were 69 admissions in total. Seven $(27 \%)$ children had two admissions, three $(12 \%)$ children had three admissions, and seven $(27 \%)$ children had four or more admissions. Table 1 presents patient characteristics, including diagnosis, age, and outcome. 
Table 1 Patient characteristics

\begin{tabular}{|c|c|c|c|c|c|c|}
\hline Diagnosis & Sex & $\begin{array}{l}\text { Age at first } \\
\text { admission }\end{array}$ & $\begin{array}{l}\text { Function on first } \\
\text { admission }\end{array}$ & $\begin{array}{l}\text { No. of PICU } \\
\text { admissions }\end{array}$ & $\begin{array}{l}\text { Duration of } \\
\text { follow up }\end{array}$ & Died during follow up \\
\hline \multicolumn{7}{|l|}{ Muscular dystrophy (32\%) } \\
\hline 1 Becker's muscular dystrophy & M & 14 y $4 \mathrm{mth}$ & Normal & 2 & $3 \mathrm{mth}$ & No \\
\hline Congenital myotonic dystrophy & $\mathrm{F}$ & 12 y $11 \mathrm{mth}$ & Mild & 1 & $5 \mathrm{mth}$ & No \\
\hline $\begin{array}{l}3 \text { Congenital muscular dystrophy unknown } \\
\text { subtype }\end{array}$ & $\mathrm{F}$ & 1 y $9 \mathrm{mth}$ & Severe & 3 & 1 y $4 \mathrm{mth}$ & Died 3rd admission \\
\hline 4 Congenital muscular dystrophy & $\mathrm{F}$ & ly $5 \mathrm{mth}$ & Severe & 2 & $2 \mathrm{mth}$ & Died on ward \\
\hline 5 Congenital muscular dystrophy & M & 2 y $5 \mathrm{mth}$ & Moderate & 1 & Died 1st admission & Died 1st admission \\
\hline 6 Congenital muscular dystrophy & M & 7 y $11 \mathrm{mth}$ & Moderate & 1 & $1 y$ & No \\
\hline 7 Duchenne's muscular dystrophy & M & 15 y $8 \mathrm{mth}$ & Severe & 1 & 1 y $11 \mathrm{mth}$ & No \\
\hline 8 Duchenne's muscular dystrophy & M & 13 y $11 \mathrm{mth}$ & Severe & 2 & 3 y $9 \mathrm{mth}$ & Died 2nd admission \\
\hline 9 Duchenne's muscular dystrophy & M & $15 y$ & Severe & 4 & 3 y $5 \mathrm{mth}$ & Died at home \\
\hline \multicolumn{7}{|l|}{ Spinal muscular atrophy (18\%) } \\
\hline 10 Spinal muscular atrophy I & $\mathrm{F}$ & $4 \mathrm{mth}$ & Severe & 1 & $3 \mathrm{mth}$ & Died at home \\
\hline 11 Spinal muscular atrophy I & $\mathrm{F}$ & $8 \mathrm{mth}$ & Severe & 1 & Died 1st admission & Died 1st admission \\
\hline 12 Spinal muscular atrophy II & M & 6 y $11 \mathrm{mth}$ & Severe & 2 & $10 \mathrm{mth}$ & No \\
\hline 13 Spinal muscular atrophy II & M & 3 y $3 \mathrm{mth}$ & Moderate & 3 & 4 y $2 \mathrm{mth}$ & No \\
\hline 14 Spinal muscular atrophy II & $\mathrm{F}$ & 2 y $9 \mathrm{mth}$ & Severe & 5 & 2 y $10 \mathrm{mth}$ & No \\
\hline \multicolumn{7}{|l|}{ Myopathy $(28 \%)$} \\
\hline 15 Idiopathic myopathy & M & 1 y $4 \mathrm{mth}$ & Mild & 7 & 7 y $3 \mathrm{mth}$ & No \\
\hline 16 Arthrogryposis/myopathy & M & $4 \mathrm{mth}$ & Severe & 2 & 2 y $11 \mathrm{mth}$ & No \\
\hline 17 Central core myopathy & M & 16 y $5 \mathrm{mth}$ & Moderate & 4 & 5 y $6 \mathrm{mth}$ & No \\
\hline 18 Central fibre type disproportion & M & 2 y $5 \mathrm{mth}$ & Mild & 1 & 2 y $10 \mathrm{mth}$ & No \\
\hline 19 Idiopathic myopathy & M & $3 \mathrm{mth}$ & Severe & 9 & 1 y $3 \mathrm{mth}$ & Died on ward \\
\hline 20 Non-progressive proximal myopathy & $\mathrm{F}$ & 11 y $10 \mathrm{mth}$ & Mild & 2 & 2 y $11 \mathrm{mth}$ & No \\
\hline 21 Pompe's disease & M & $2 y$ & Mild & $\overline{1}$ & $3 \mathrm{mth}$ & Died at home \\
\hline 22 Nemaline rod myopathy & M & 4 y $6 \mathrm{mth}$ & Normal & 1 & $10 \mathrm{mth}$ & No \\
\hline \multicolumn{7}{|l|}{ Neuropathy (11\%) } \\
\hline 23 Charcot Marie tooth & $\mathrm{F}$ & 1 y $5 \mathrm{mth}$ & Mild & 1 & 1 y $4 \mathrm{mth}$ & No \\
\hline $\begin{array}{l}24 \text { Congenital demyelinating peripheral } \\
\text { neuropathy }\end{array}$ & $\mathrm{F}$ & 10 y $10 \mathrm{mth}$ & Moderate & 2 & $10 \mathrm{mth}$ & No \\
\hline $\begin{array}{l}25 \text { Hereditary motor and sensory neuropathy } \\
\text { type II }\end{array}$ & M & $16 y$ & Moderate & 1 & $\begin{array}{l}\text { Died on day of } \\
\text { discharge }\end{array}$ & Died at home \\
\hline \multicolumn{7}{|l|}{ Other (11\%) } \\
\hline 26 ARTS syndrome & M & 3 y $2 \mathrm{mth}$ & Moderate & 5 & 2 y $3 \mathrm{mth}$ & No \\
\hline 27 ARTS syndrome & $M$ & 1 y $9 \mathrm{mth}$ & Mild & 3 & 2 y $3 \mathrm{mth}$ & No \\
\hline \multirow{2}{*}{28 Friedreich's ataxia } & $\mathrm{F}$ & $15 y$ & Mild & 1 & $2 y$ & No \\
\hline & & & Total admissions & 69 & & \\
\hline
\end{tabular}

\section{All admissions}

Unplanned admissions versus planned admissions Forty seven (66\%) admissions were unplanned. Length of stay was significantly longer for unplanned compared to planned admissions (7 $(2-14)$ days $v 2(1-3.3)$ days $\left(\chi^{2}{ }_{1}\right.$ $12.5, \mathrm{p}=0.001))$. Ninety six per cent of unplanned admissions were less than 28 days, $75 \%$ were less than 14 days. Children undergoing unplanned admissions were significantly sicker with higher initial PRISM scores ((5.2 (3-12) for unplanned admissions $v 1.4(0.5-2.3)$ for planned admissions $\left.\left(\chi_{1}^{2} 15, p=0.001\right)\right)$ and more likely to need continuous ventilation $(75 \% v 55 \%)$ while in the PICU $\left(\chi_{1}^{2} 13, \mathrm{p}=0.001\right)$ (table 2).

Forty four (93\%) of the unplanned admissions were for respiratory deterioration, including 12 post-respiratory arrest. The other three unplanned admissions were for cellulitis $(n=1)$ and cardiac failure $(n=2)$. Twenty two admissions were planned, 17 (77\%) for elective surgery and five $(23 \%)$ in conjunction with the respiratory support service for commencement or adjustment of nocturnal ventilation. In the final section of results we present longitudinal follow up data from the first admission; this includes both planned and unplanned admissions-12 children whose first admission was planned, and four who had a subsequent unplanned admission. For the remainder of the results section, only data relating to unplanned admissions are presented.

\section{All unplanned admissions}

\section{Pre-PICU level of function}

There was no significant difference in length of stay, need for continuous ventilation, duration of ventilation, or PRISM score when admissions were analysed according to level of function immediately prior to an each unplanned PICU admission (table 2).

\section{Acute respiratory infection}

Signs of acute respiratory infection were found within 48 hours of presentation for $30(64 \%)$ of the 47 unplanned admissions. Acute infective organisms were found in the respiratory tract on $13 / 30(43 \%)$ occasions. They were respiratory syncytial virus (RSV) $(n=4)$, rhinovirus $(n=3)$, influenza $(\mathrm{n}=2)$, Mycoplasma $(\mathrm{n}=2)$, Staphylococcus aureus $(\mathrm{n}=1)$, and Haemophilus influenzae $(\mathrm{n}=1)$. Only two patients had positive cultures in the absence of other signs of infection (one RSV and one Haemophilus influenzae). There was no significant difference in duration of stay, duration of ventilation, or PRISM scores between the unplanned admissions with and without signs of acute infection (table 2).

\section{Ventilation}

Continuous ventilation was used in 35/47 (74\%) unplanned PICU admissions. Continuous ventilation was entirely noninvasive in three $(6 \%)$. Tracheostomies were performed during three admissions: one to facilitate nocturnal ventilation 
Table 2 Length of stay, need for ventilation, and PRISM scores for all 69 admissions

\begin{tabular}{|c|c|c|c|c|c|c|}
\hline & $\begin{array}{l}\text { No. of } \\
\text { admissions }\end{array}$ & Age & $\begin{array}{l}\text { Median days of } \\
\text { admission (Q1-3) }\end{array}$ & Median PRISM & $\begin{array}{l}\text { Number } \\
\text { continuously } \\
\text { ventilated }\end{array}$ & $\begin{array}{l}\text { Median ventilation } \\
\text { (days) (Q1-3) }\end{array}$ \\
\hline \multicolumn{7}{|l|}{ All admissions } \\
\hline Planned & 22 & $6.4(2.1-14.2)$ & $2.0(1-3.3)$ & $1.4(0.5-2.3)$ & $12 / 22(55 \%)$ & $0.7(0.3-2)$ \\
\hline \multirow{2}{*}{ Unplanned } & 47 & $3.5(1.5-7)$ & $7.0(2-14)$ & $5.2(3-12)$ & $35 / 47(75 \%)$ & $5(3-12)$ \\
\hline & & $p=0.19$ & $p=0.001$ & $p=0.001$ & $p=0.001$ & $p=0.001$ \\
\hline \multicolumn{7}{|l|}{ Unplanned: infection } \\
\hline Acute infection & 30 & $1.7(3.5-4.7)$ & $8.5(4-14)$ & $5.8(3.5-12)$ & $24 / 30(80 \%)$ & $7.5(4-12.8)$ \\
\hline No infection & 14 & $2(0.9-9.5)$ & $5(2-11)$ & $4.4(3-14)$ & $11 / 14(79 \%)$ & $5(3-9.5)$ \\
\hline \multirow[t]{2}{*}{ Non-respiratory problem } & 3 & & 2 & Not available & 0 & 0 \\
\hline & & $p=0.41$ & $p=0.17$ & $p=0.93$ & $p=0.77$ & $p=0.23$ \\
\hline \multicolumn{7}{|l|}{ Outcome at follow up } \\
\hline Dead & 25 & & $4(1-9.8)$ & $3.3(1-8)$ & $18 / 25(72 \%)$ & $4(2-7.6)$ \\
\hline Alive & 44 & & $4(2-9.5)$ & $4(1.5-10.5)$ & $29 / 44(65 \%)$ & $3.3(1.4-8.8)$ \\
\hline \multicolumn{7}{|l|}{ Unplanned: function } \\
\hline Severe impairment & 24 & $2.5(0.9-6.5)$ & $6.5(3-13)$ & $5.8(3.3-18.5)$ & $18 / 24(75 \%)$ & $4.5(2.8-11.3)$ \\
\hline Moderate impairment & 9 & $4.5(3.4-18)$ & $4(1.5-13)$ & $3.2(4.8-6.7)$ & $6 / 9(67 \%)$ & $7(3.5-15)$ \\
\hline Mild impairment & 12 & $2.7(1.7-4.4)$ & $10(4.3-16.3)$ & $12(2.2 .-18)$ & $11 / 12(92 \%)$ & $8.9(5-12)$ \\
\hline \multirow[t]{2}{*}{ Normal (values) } & 2 & $14.3,14.4$ & 2,7 & 0 & 0 & 0.35 \\
\hline & & $p=0.03$ & $p=0.59$ & $p=0.18$ & $p=0.46$ & $p=0.36$ \\
\hline
\end{tabular}

before non-invasive ventilation was widely used, one for airway toilet, and one to relieve obstruction from subglottic stenosis. Continuous ventilation was via an existing tracheostomy during a further seven (15\%) admissions. In five $(11 \%)$ admissions only nocturnal NIPPV was used. This combined gives a total of $40(85 \%)$ admissions requiring some form of ventilatory support.

Eighteen $(38 \%)$ unplanned admissions were discharged to the ward continuing on some form of respiratory support, mostly nocturnal NIPPV $(n=14)$. Following seven $(15 \%)$ admissions, this support was the same as that used prior to that admission. Following 11 (23\%) unplanned admissions, this was novel respiratory support continued outside the PICU for the first time. On four of these occasions NIPPV was weaned prior to final discharge from hospital.

\section{Death during PICU admission}

Four patients (6\% of all admissions) died during their PICU admission. All these patients were unplanned admissions (9\% of all unplanned admissions) requiring invasive ventilation. Three had severe limitation of function and one (case 5) had moderate limitation. These proportions differ from the distribution of function in the cohort $(39 \%$ had severe limitation of function), but the numbers are too small for statistical comparison. Thirty per cent of children with severe limitation of function $(n=3 / 11)$ died during a PICU admission compared to $14 \%$ of children with moderate limitation of function $(n=1 / 7)$ and no children with mild or normal function $(n=0 / 10)$.

All four children died after a decision was made to withdraw support. Two had hypoxic brain injury secondary

Table 3 Survivors versus non-survivors at follow up

\begin{tabular}{lll}
\hline & Dead at follow up & Alive at follow up \\
\hline Number of children & 10 & 18 \\
Age at first admission & $1.9(0.9-11)$ & $3.2(1.7-12.4)$ \\
Total PICU admission & $12(3.5-22.5)$ & $9(4-18)$ \\
days per child & & \\
Function & $7(70 \%)$ & $4(22 \%)$ \\
$\quad$ Severe & $2(20 \%)$ & $5(28 \%)$ \\
Moderate & $1(10 \%)$ & $2(11 \%)$ \\
Mild & 0 & $3(17 \%)$ \\
Normal & $1(10 \%)$ & $9(50 \%)$ \\
Home respiratory support & 1 & \\
\hline
\end{tabular}

to pre-hospital respiratory arrests (a girl aged 3 years already on home non-invasive respiratory support (case 3 ), and a boy aged 2 years 8 months (case 5), both with congenital muscular dystrophy). The third was an 8 month old girl (case 11) with little spontaneous movement admitted with respiratory distress and diagnosed with SMAl after admission. Care was withdrawn on day 8 once the diagnosis was confirmed. The final death was a 17 year old boy (case 8) with DMD; he had one previous planned PICU admission. He was a poor attendee at clinic follow up and presented in acute respiratory failure following a chest infection, with no interim review for three years. Three attempts were made to wean his ventilation and all were unsuccessful. The patient participated in the decision to withdraw ventilation rather than proceed to tracheostomy. He died after a 42 day admission.

\section{Follow up from first admission (planned and unplanned)}

Survival after discharge

Twenty six (93\%) children survived to discharge following their first PICU admission. At follow up, 18 (64\%) were still alive. Median duration of follow up for survivors was 2 years 3 months (range 3 months to 7 years 5 months) from first PICU admission.

Two children died during their first admission and a further eight died after discharge. Median time to death was nine months (range one day to 3 years 7 months) following first PICU admission. Two children died during later PICU admissions, and have been discussed above. Two deaths were in the ward and four at home. The first ward death was a girl (case 4) with undiagnosed weakness admitted to PICU with respiratory distress and managed conservatively because of the severity of her underlying disorder. She died seven days after discharge from her second PICU admission without returning home. Congenital muscular dystrophy was diagnosed at postmortem examination. The second was a 19 month old boy (case 19) whose family eventually declined further admissions after his ninth PICU admission. However, they did not feel comfortable managing their child at home and he was admitted to the ward a further three times in the six weeks between his final discharge from the PICU and death. Four children died at home-one was unexpected. A boy (case 25) with hereditary motor and sensory neuropathy who was admitted for overnight observation following anaesthesia for dental extraction died suddenly at home on 
the day after the procedure. The postmortem examination report was not available.

Of the six children who died out of PICU, four followed an active decision, with participation of the family, not to readmit to PICU. Seventy per cent of those who died were in the severe functional group compared with 4/18 of survivors. One child (case 21) with Pompe's had only mild functional impairment but was known to have cardiac involvement and was found dead at home. Postmortem examination was consistent with pneumonia.

\section{Respiratory support survivors versus non-survivors (table 3)}

Nine of the surviving 18 (50\%) children needed respiratory support at home at some stage during the follow up period. One was on nocturnal ventilation via a tracheostomy and eight were on NIPPV. Three children where discharged to the ward with NIPPV, but it was discontinued prior to discharge, and not required at home. Five never needed home respiratory support. One (case 23) had been on NIPPV, but this was discontinued after the first PICU admission once her upper airway obstruction was surgically relieved.

Ten children died during the follow up period. Only one child (case 3 ) had been on home NIPPV. Two children had tracheostomies (case 15 and case 9) but they were not required for IPPV. The seven remaining children did not receive home NIPPV prior to death.

\section{DISCUSSION}

This study is the largest series of its kind and the first to look at long term outcome following PICU admission in children with NMD. There are two principle findings: (1) $9 \%$ of unplanned admissions to the PICU resulted in death prior to discharge from our unit, all after withdrawal of treatment; and (2) the majority of unplanned admissions were not prolonged-75\% less than 14 days and 96\% less than a month. Nocturnal respiratory support was commenced in the PICU and continued after discharge for $23 \%$ of unplanned admissions, in one case via a tracheostomy and the remainder non-invasively. There were no cases requiring continuous ventilation outside the PICU. This challenges the preconception held by many physicians that children with chronic NMD should not be admitted to the PICU during episodes of acute deterioration because of subsequent inability to wean ventilation, or discharge from the PICU.

While there were a greater number of deaths in children with severe impairment of function, the numbers in our study are too small to reach statistical significance. Severity of functional impairment was not related to the length of PICU admission, need for invasive ventilation, or severity of illness. Planned admissions were usually postoperative, for procedures performed electively during a period of good health. The majority of unplanned admissions, however, were for acute respiratory failure, often associated with evidence of respiratory tract infection. These admissions were associated with higher PRISM scores and a greater requirement for invasive ventilation. The presence of acute respiratory infection was not associated with a worse outcome compared to children with respiratory decompensation with no evidence of an acute infection.

Overall 10 of the 28 children (36\%) with NMD admitted to the PICU have died. Of these, $70 \%$ were in the severe functional group supporting the association between severe skeletal muscle weakness and poor respiratory prognosis. It has previously been shown that poor respiratory reserve is associated with reduced survival. In DMD, decline in forced vital capacity of less than $500 \mathrm{ml}$ is associated with imminent death. ${ }^{4}$ Anticipating respiratory deterioration and forward planning of respiratory support and palliative care has been essential. ${ }^{5}$ A decision not to seek further admissions to intensive care had been made between the families and the treating physicians for four of the six children who died outside the PICU. In our experience younger children tended to die in hospital rather than at home, possibly reflecting the shorter time parents had to adjust to the inevitable death of their child, particularly if diagnosis was only made after admission. This group accounted for most of those who died during their first PICU admission or were transferred to the ward and died. The children who died at home tended to be older and may have had several PICU admissions but as their disorder progressed, further PICU admission and aggressive treatment was decided against. In these cases there was usually time to arrange appropriate home supports and palliative care. In a smaller proportion of cases children may be admitted to the PICU and commenced on respiratory support before potential entrapment is recognised. ${ }^{67}$ Our study did not identify any parameters associated with the need for invasive ventilation or duration of stay. It is difficult to predict with any certainty which children will improve with invasive intervention and support. Thus in some cases it remains necessary to commence support which is later withdrawn. Withdrawal of care preceded death in all four children who died in PICU. This finding is consistent with a previously published report that almost two thirds of deaths in PICU occur after withdrawal of treatment, reinforcing that this dilemma is not a problem isolated to patients with NMD. ${ }^{89}$

In a study of children requiring ventilation for more than a month, $27 \%$ had neuromuscular failure as their underlying problem. ${ }^{2}$ Seven of the patients in that study met our diagnostic criteria for chronic NMD. Their length of stay ranged from 36 to 910 days. The authors commented that many admissions were prolonged by the delay in finding a suitable discharge location for children who were ventilator dependent. While our study was not designed as an audit of all patients requiring long term ventilation, we did examine the length of stay in all children with NMD admitted to the PICU. The longest admission in our study was 42 days; all other admissions were less than 28 days. Our patient population and management practices may account for some of these differences. We only had one patient needing ongoing invasive ventilation and requiring more complex discharge planning. A home ventilation programme, established in 1989, is available to support patients on nocturnal ventilation after discharge from PICU. Our respiratory support service is actively involved in the management of all of the children who survived their first admission but subsequently needed home respiratory support. In this review half of the surviving children eventually needed home respiratory support; this proportion can be expected to increase as experience with NIPPV improves. If desired, children can now be offered chronic respiratory support earlier in the course of their disease, prior to an episode of acute decompensation. With an established support service non-invasive ventilation can be used to manage acute illness at home; ${ }^{10-14}$ however this was not available in the time period studied. Ultimately this may provide families with an alternative between conservative management and PICU admission. As our study has been unable to identify any predictive factors for poor outcome, families would need support to cope with the possible death of their child at home. Future studies may assist stratifying children to high and low risk of death during an episode of acute deterioration.

This study did not examine the number of patients with NMD who were never offered PICU admission. Although it is clear that children with severe impairment of function were not completely excluded from our unit, the results may be 
biased by the selective admission of patients felt to have a better prognosis. Future studies which included all children with NMD referred to the PICU would be required to clarify this.

In conclusion, this study is the first to report outcome from PICU admission specifically for children with NMD. Our results suggest that all children with underlying NMD should be provided with acute respiratory support, in the anticipation that they are likely to recover. However, repeat admissions and chronic respiratory failure are likely and should be actively anticipated. Future studies will be required to clarify whether specific predictive factors exist in this patient group with regard to acute PICU outcomes and may help the decision making process for intensivists and the physicians caring for children with NMD. Clinicians' and managers' fears of long stay patients tying up precious resources are based on scanty evidence and may not be justified in the current medical environment.

\section{Authors' affiliations}

K Yates, M Festa, J Gillis, Department of Paediatric Intensive Care, The Children's Hospital at Westmead (Royal Alexandra Hospital for Children), Sydney, Australia

K Waters, Department of Respiratory Support Service, The Children's Hospital at Westmead (Royal Alexandra Hospital for Children), Sydney, Australia
K North, Neurogenetics Research Unit, The Children's Hospital at Westmead (Royal Alexandra Hospital for Children), Sydney, Australia

\section{REFERENCES}

Birnkrant DJ, Pope JF, Eiben RM. Management of the respiratory complications of neuromuscular disease in the paediatric intensive care unit. J Child Neurol 1999;14:139-43.

2 Fraser J, Henrichsen T, Mok Q, et al. Prolonged ventilation as a consequence of acute illness. Arch Dis Child 1998:78:253-6.

3 Pollack MM, Ruttimann UE, Getson PR. Pediatric risk of mortality (PRISM) score. Crit Care Med 1988;16:1110-16.

4 Hilton T, Orr RD, Perkin RM, et al. End of life care in Duchenne muscular dystrophy. Paediatr Neurol 1993:9:165-77.

5 Miller JR, Colbert AP, Osberg JS. Ventilator dependency: decision making, daily functioning and quality of life for patients with Duchenne muscular dystrophy. Dev Med Child Neurol 1990;32:1078-86.

6 Gillis J, Tibbals J, McEniery J, et al. Ventilator dependent children. Med J Aust 1989;150:10-14.

7 Gillis J, Kilham H. Entrapment. Crit Care Med 1990;18:897.

8 Balfour-Lynn IM, Tasker RC. Futility and death in paediatric medical intensive care. J Med Ethics 1996;22:279-81.

9 Moss MM, Fisher DH. Futility in paediatric intensive care. Baillieres Clin Anaesthesiol 1998;12:163-72.

10 Gozal D. Pulmonary manifestations of neuromuscular disease with special reference to Duchenne muscular dystrophy and spinal muscular atrophy. Paediatr Pulmonol 2000;29:141-50.

11 Schramm CM. Current concepts of respiratory complications of neuromuscular disease in children. Curr Opin Paediatr 2000;12:203-7.

12 Tzeng AC, Bach JR. Prevention of pulmonary morbidity for patients with neuromuscular disease. Chest 2000;118:1390-6.

13 Niranjan V, Bach JR. Noninvasive management of paediatric neuromuscular ventilatory failure. Crit Care Med 1998;26:2061-5.

14 Birnkrant D, Pope JF, Eiben RM. Paediatric noninvasive nasal ventilation. J Child Neurol 1997;12:231-6. 